\title{
АНАЛІЗ ЕКОЛОГО - ХІМІЧНОГО СТАНУ ГРУНТІВ М.ОДЕСА ДЛЯ ЦІЕЙ МОДЕЛЮВАННЯ ЯКОСТІ ГРУНТІВ УРБАНІЗОВАНИХ ТЕРИТОРІЙ
}

\author{
В. Ільіна \\ Одеський державний екологічний університет
}

Місто Одеса є одним з найбільш навантажених урбанізованих територій. Це пов язано із багатьма факторами, основним з яких є відсутність метрополітену, що викликає значне навантаження на грунтовий покрив за рахунок автоторанспортних та інших транспортних систем. За рахунок иього формується біля 80\% забруднення атмосферного повітря, водного середовища та грунтово - рослинного покриву, а також погіршуються еколого - хімічні характеристики якості грунтів, що в свою чергу призводить до погіршення якісних та кількісних характеристик екосистеми міста в иілому. $B$ рамках роботи виконано аналіз основних характеристик грунту які визначають його еколого - хімічний стан, за даними 2012 по 2016 роки. На сучасному етапі розвитку екологічної науки актуальним $є$ питання оцінки стану територій за допомогою математичного моделювання, яке ураховує більшість факторів навколишнього середовища $i$ дає можливість прогнозування можсливх змін їх стану з достатнім ступенем імовірності. У подальшому, за допомогою математичної моделі, буде виконано оцінку стану грунтів урбанізованих територій( на прикладі міста Одеса) при сучасному рівні антропогенного навантаження.

Ключові слова: урбанізовані території, якість грунтів, математична модель, еколого - хімічна оцінка, антропогенне навантаження.

Вступ. На території міста виділяються природно - антропогенні ландшафтні комплекси різних рангів. Власне, місто - це ландшафт, який успадкував від природного тільки геологічну основу, головні рисі рельєфу i зональні особливості клімату. В ньому перетворені майже всі природні компоненти, а також природна ландшафтна структура. При забудові проводиться нівелювання поверхні і має місце різка зміна характеру гірських порід. Техногенні грунти, які підстилаються будівельним сміттям, характеризуються підвищеною дренажністю, низькою вологістю та ін. Бетонні та асфальтові покриття практично знищують усе живе в грунті [1]. В результаті складної взаємодії природних i антропогенних компонентів і елементів формуються специфічні ландшафтно-антропогенні комплекси різного таксономічного рангу морфологічні одиниці міського ландшафту.

Проблема. Місто Одеса $є$ однією 3 найбільш проблемних територій 3 точки зору антропогенного навантаження та особливостей кліматичних умов, тому проблема оцінки стану грунтів є дуже актуальною. 
Аналіз останніх досліджень і публікацій. Питанням оцінки стану урбанізованих територій займалися багато авторів [1]. При цьому були ураховані основні містобудівні характеритики [2].

Мета досліджень. Виконати оцінку сучасного стану грунті урбанізованої території ( на прикладі м.Одеса) для цілей математичного моделювання, що дозволить надати практичні рекомендації що до зменшення навантаження на грунтовий покрив .

Результати досліджень. Структура антропогенного ландшафту характеризує спосіб його внутрішньої організації, зв'язків компонентів, що його складають і ПАТК (природно-антропогенний територіальний комплекс) та більш низьких рангів. Основними структурно-функціональними частинами міських геосистем є природні й антропогенні компоненти та елементи, морфологічні одиниці ландшафтів. Місто Одеса $\epsilon$ одним за найбільш навантажених в Одеській області за рахунок значної інтенсивності транспортних потоків та великої кількості підприємств теплозабезпечення. На рисунках 1-7 за осередненими даними 2012 - 2016 року наведені показники якості грунтів у різних районах міст.

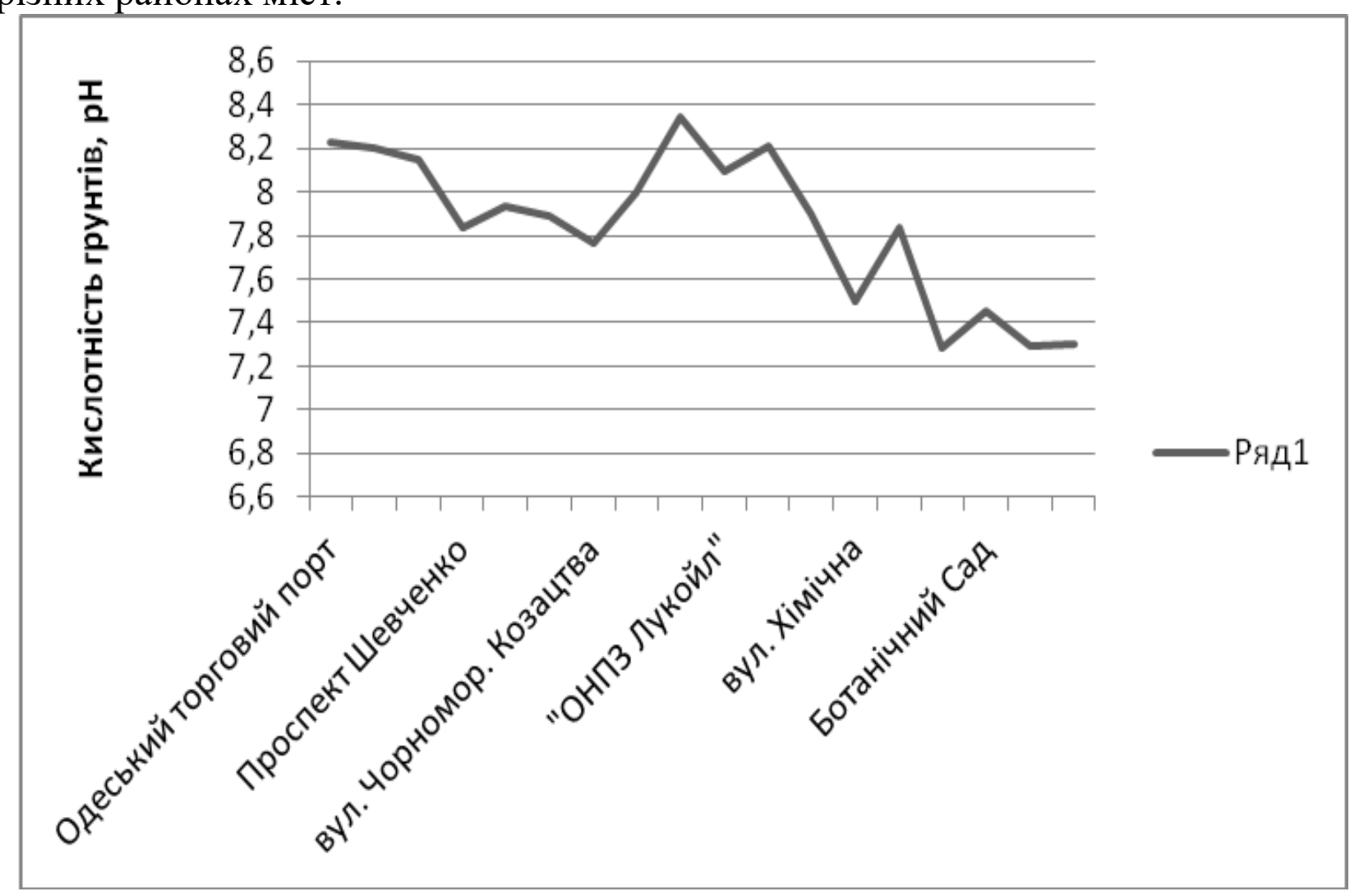

Рис. 1. Значення кислотності грунтів у різних районах м. Одеса.

3 рисунку видно, що найбільші значення кислотності грунтів по місту Одеса спостерігалися у районі «ОНПЗ Лукойл», найменші у районі Ботанічного Саду. В середньому вони склали 7,8. 
Agrarian Bulletin of tte Black Sea Littoral. 2020, Issue 97

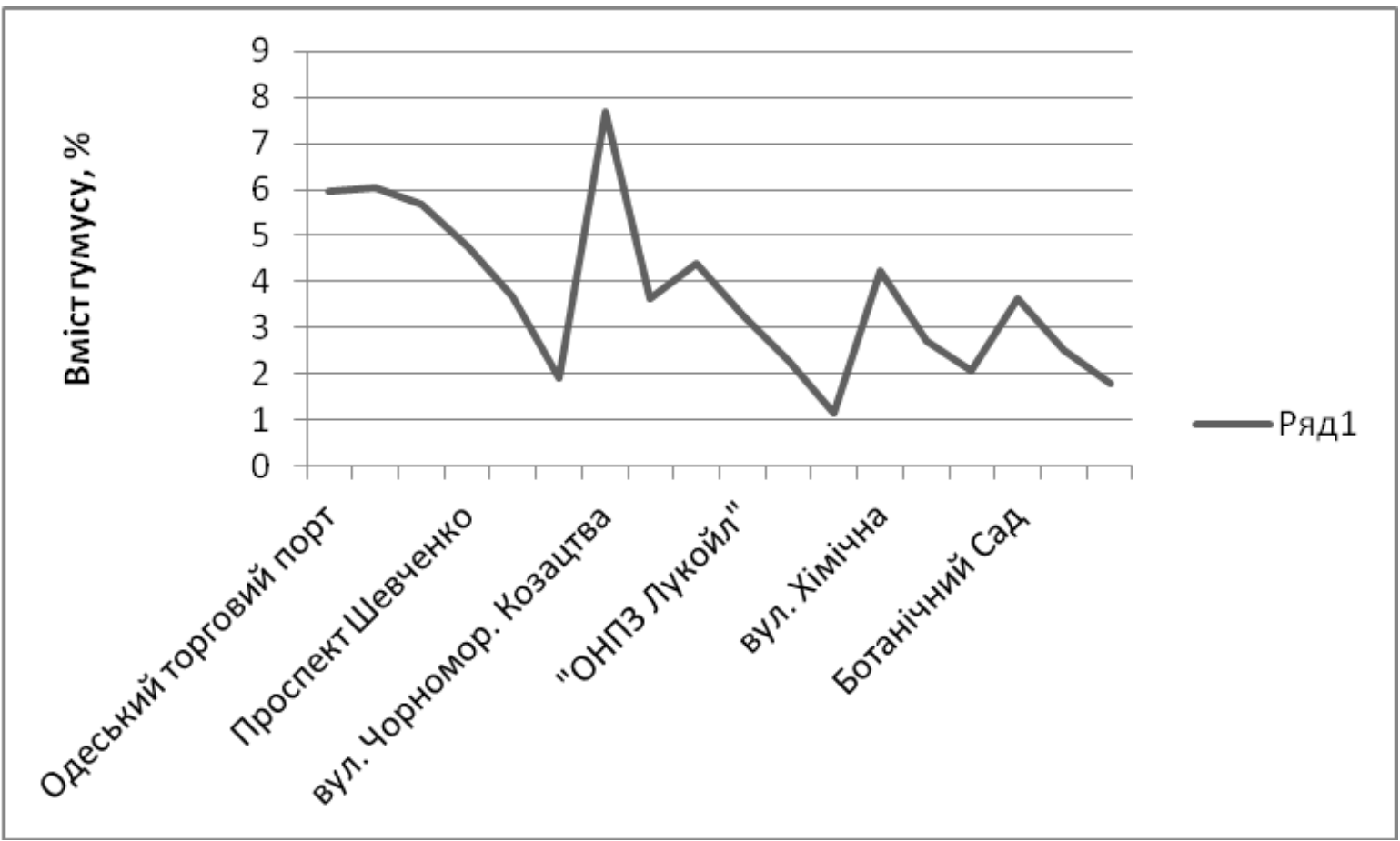

Рис. 2. Значення вмісту гумусу у різних районах м. Одеса

3 рисунку видно, що найбільші значення вмісту гумусу по місту Одеса спостерігалось у районі вул. Чорноморського Козацтва, найменші у районі вул. Хімічна. В середньому вони склали $4,5 \%$.

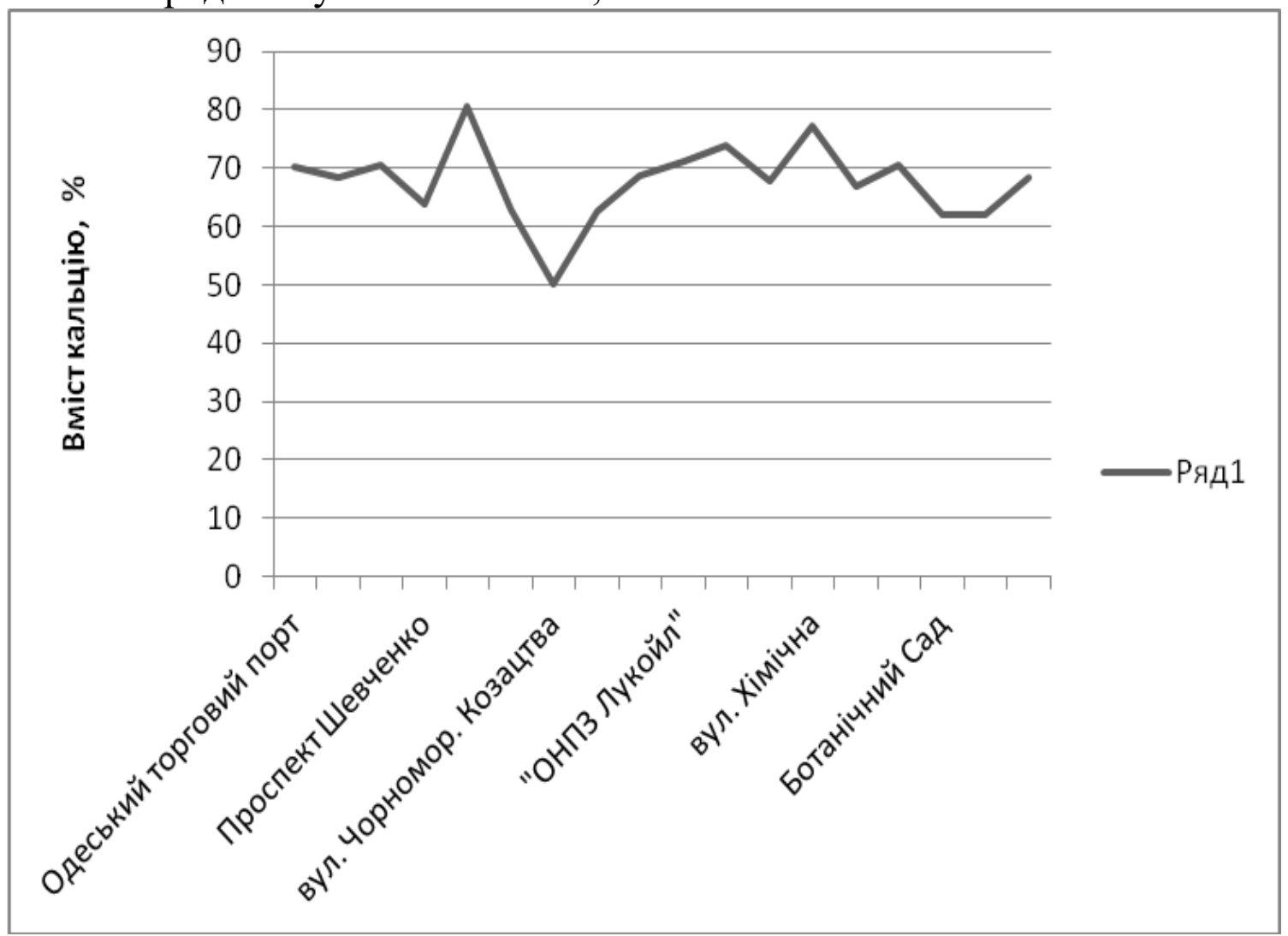

Рис. 3. Значення вмісту кальцію у різних районах м. Одеса. 
3 рисунку видно, що найбільші значення вмісту кальцію по місту Одеса спостерігалось у районі Проспекту Шевченко, найменші у районі вул. Чорноморського Козацтва. В середньому вони склали $65 \%$.

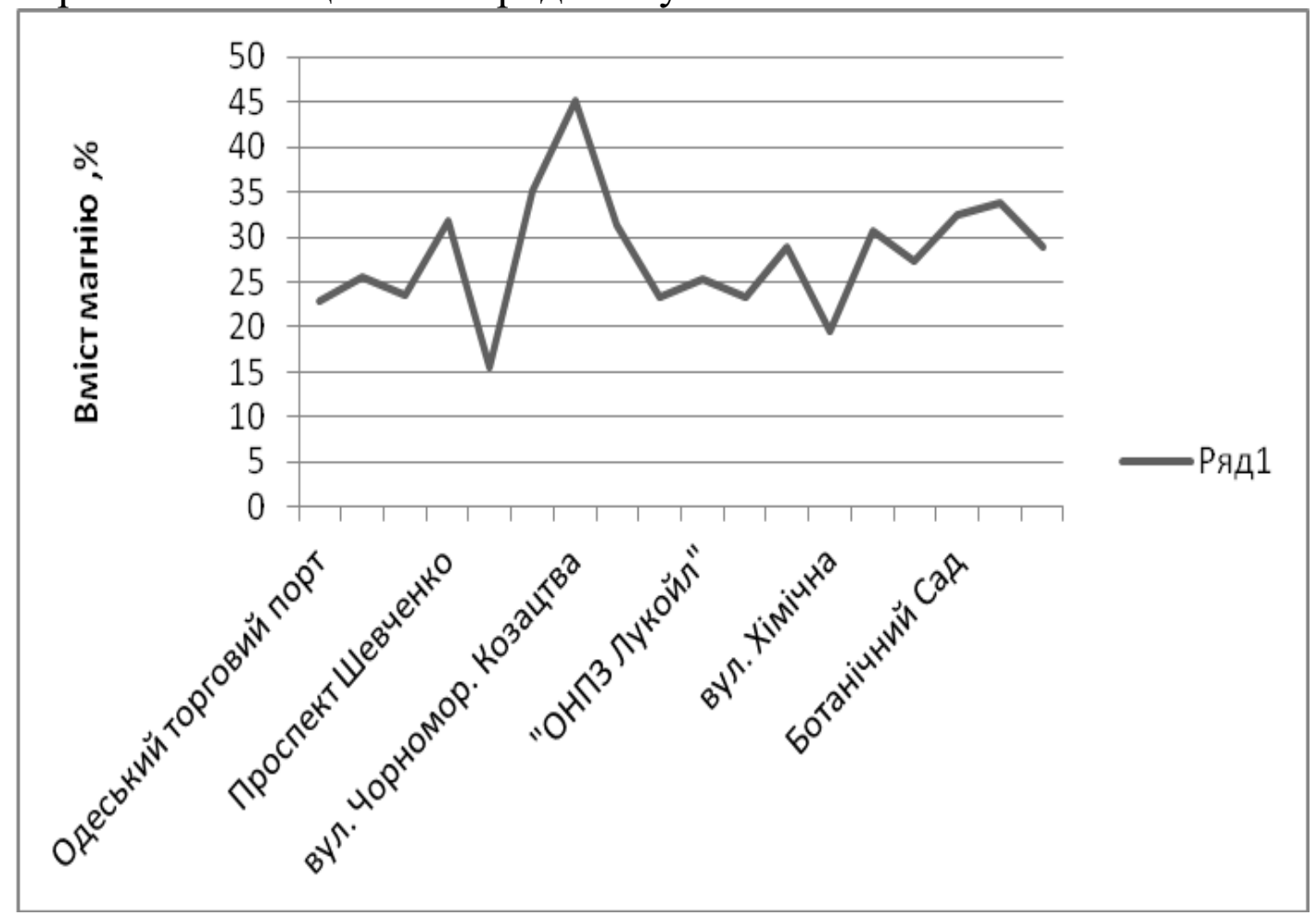

Рис. 4. Значення вмісту магнію у різних районах м. Одеса.

3 рисунку видно, що найбільші значення вмісту магнію по місту Одеса спостерігалось у районі вул. Чорноморського Козацтва, найменші у районі Проспекту Шевченко. В середньому вони склали 30 \%.

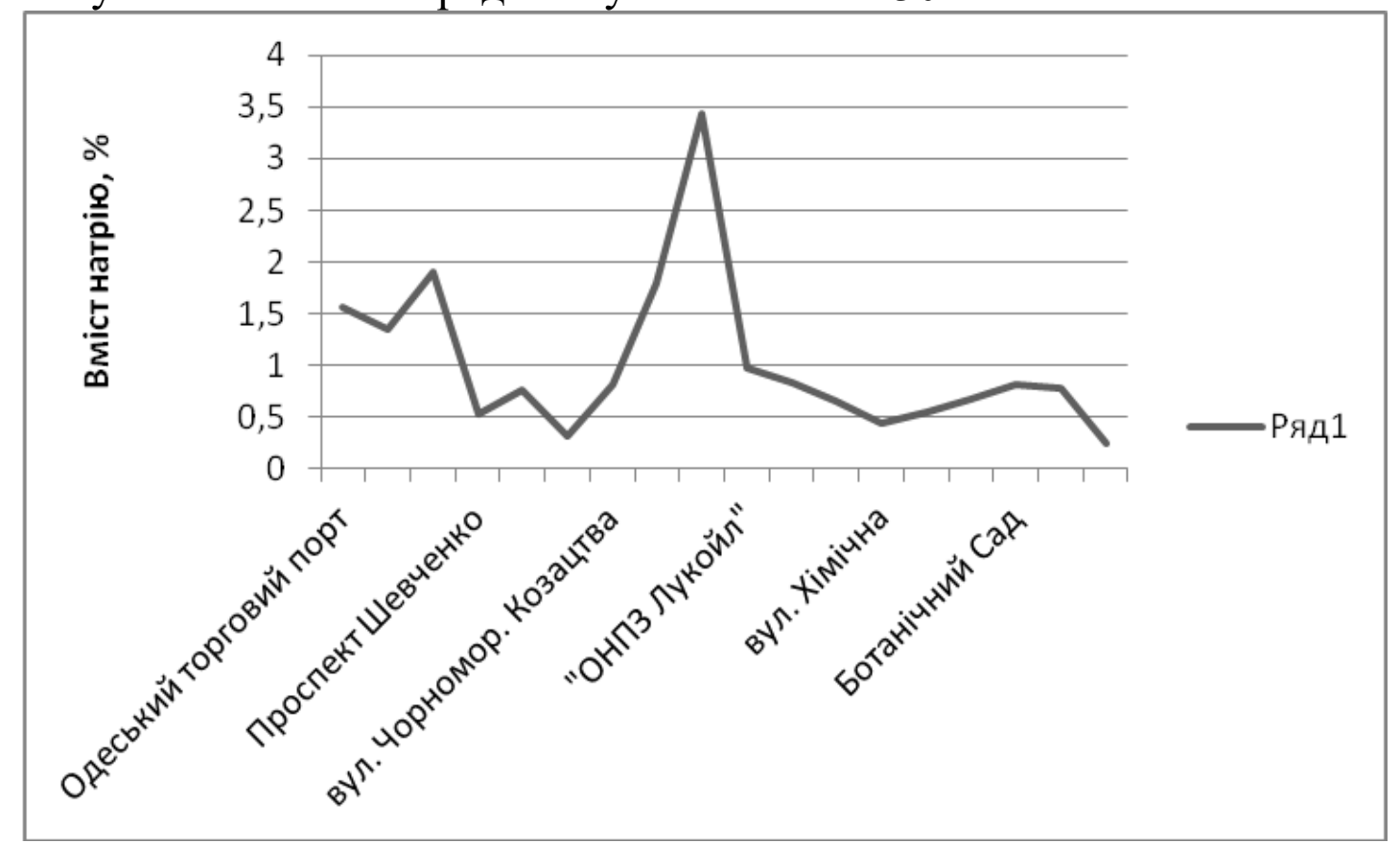

Рис.5. Значення вмісту натрію у різних районах м. Одеса. 
3 рисунку видно, що найбільші значення вмісту натрію по місту Одеса спостерігалось у районі вул. Чорноморського Козацтва, найменші у районі Ботанічного Саду. В середньому вони склали $2,04 \%$.

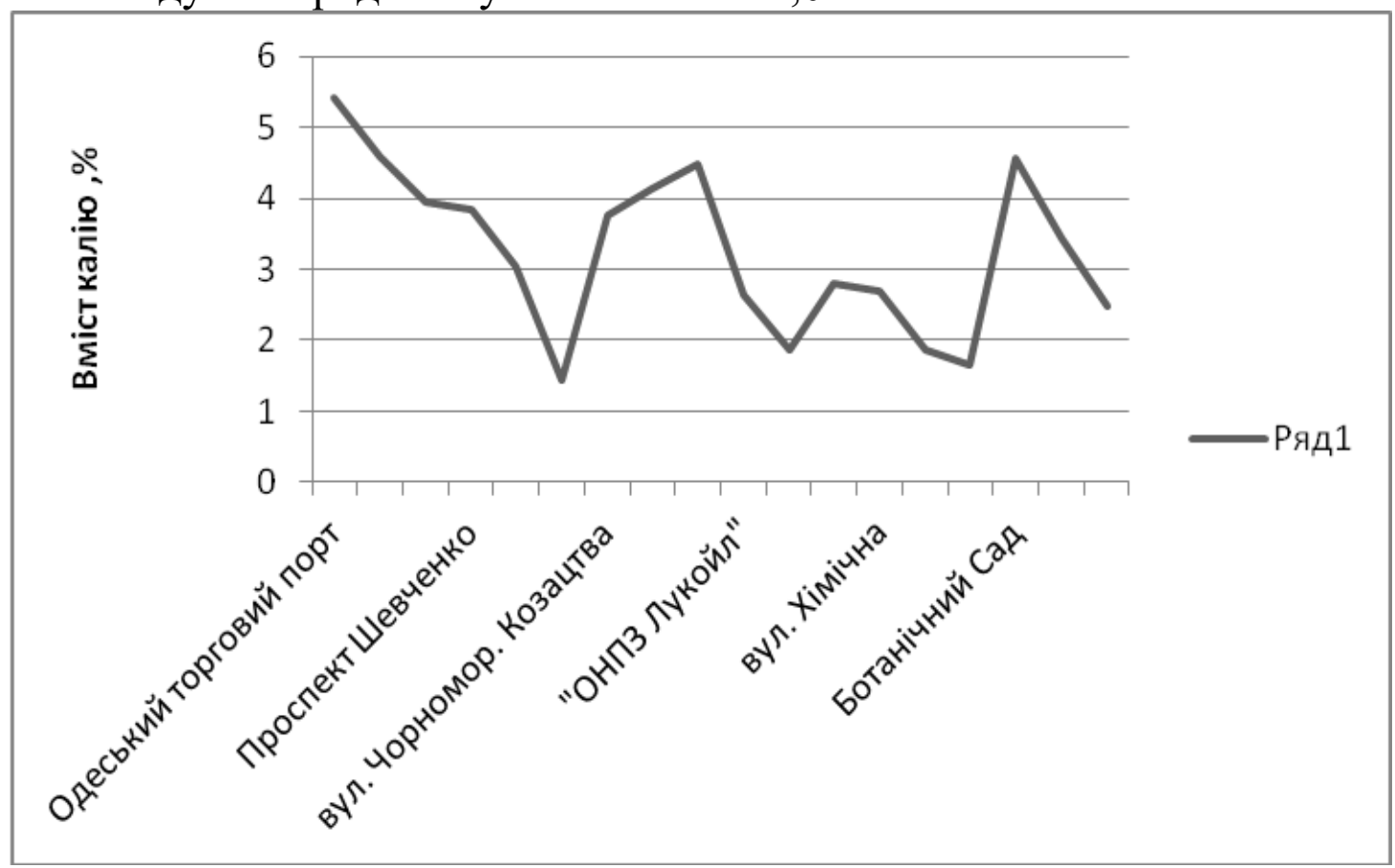

Рис. 6. Значення вмісту калію у різних районах м. Одеса.

3 рисунку видно, що найбільші значення вмісту калію по місту Одеса спостерігалось у районі Одеського торгового порту, найменші у районі Проспекту Шевченко. В середньому вони склали 3,43 \%.

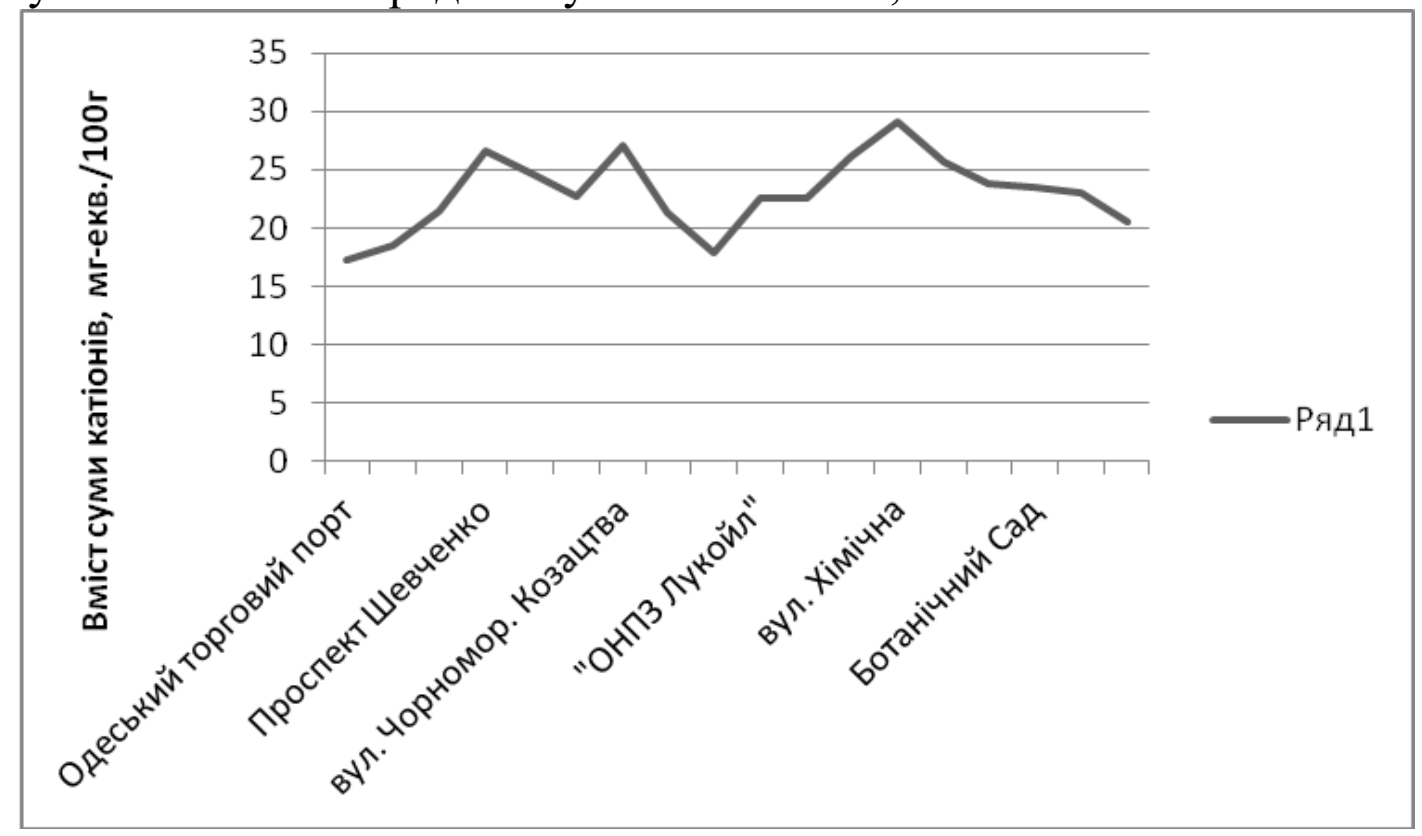

Рис. 7. Значення вмісту суми катіонів у різних районах м. Одеса.

3 рисунку видно, що найбільші значення вмісту суми катіонів по місту Одеса спостерігалось у районі вул. Хімічна, найменші у Одеського торгового порту. В середньому вони склали 23,2 \%. Одним 3 основних процесів, що 
моделюються, є процеси вологоперенесення у грунті. Рівняння потоку води в системі "грунт - корінь" розглядається аналогічно одночасно як насичене $\mathrm{i}$ ненасичене середовище [3] :

$$
\frac{\partial \psi}{\partial t}=\frac{1}{C(\psi)} \frac{\partial}{\partial z}\left[K(\Theta)\left(\frac{\partial \psi}{\partial z}+1\right)\right]-\frac{S(\psi)}{C(\psi)},
$$

де $\psi$ - потенціал тиску грунтової вологи; $C(\psi)=\frac{d \Theta}{d \psi}$ - диференціальна вологоємність; $K(\Theta)$ - гідравлічна провідність; $\Theta$ - об'ємна вологість; $\mathrm{S}(\psi)$ поглинання вологи коренями; $t$ - час; $z$ - вертикальна координата.

У подальшому будуть ураховані інші складові, які впливають на формування якісних та кількісних характеристик грунтів урбанізованих територій, у тому числі вміст основних забруднювальних елементів, до яких відносяться важкі метали, радіонукліди, пестициди та нафтопродукти.

Висновки. Проаналізувавши стан грунтів міста Одеса за еколого хімічними показниками, найбільше значення кислотності грутнів та основних вмісту іонів отримані для промислових районів міста та найменші значення для рекреаційних зон, до яких належить Ботанічний Сад. В цілому Одеса і Одеська область мають досить великий потенціал, 3 точки зору використання грунтового покриву за своїми еколого - агрохімічним характеристиками.

\title{
ЛIТЕРАТУРА
}

1. Жовинский Э.Я., Кураева И.В. Геохимия тяжелых металлов в почвах Украины. - Київ: Наукова думка, 2002. - 213 с.

2. Екология города. Учебник. Под ред. Ф.В. Стольберга. - К.: Либра, 2000. -464 c.

3. Л.М. Полетаєва, С.М. Юрасов, В.Г. Ільїна. Моделювання та прогнозування стану довкілля: Конспект лекцій. - Одеса: «ВМВ», 2006. - 181с.

\section{АНАЛИЗ ЭКОЛОГО - ХИМИЧЕСКОГО СОСТОЯНИЯ ПОЧВЫ Г.ОДЕСА ДЛЯ ЦЕЛЕЙ МОДЕЛИРОВАНИЯ КАЧЕСТВА ПОЧВ УРБАНИЗИРОВАННЫХ ТЕРРИТОРИЙ}

\author{
Ильина В.
}

Город Одесса является одной из самых нагруженных урбанизированных территорий. Это связано со многими фракторами, основнылми из которых является отсутствие метрополитена, что вызывает значительную нагрузку на почвенный покров за счет автоторанспортних и других транспортных систем. За счет этого формируется около 80\% загрязнения атмосферного воздуха, водной среды и почвенно - растительного покрова, а также ухудшаются эколого - химические характеристики качества почв, в свою очередь приводит $к$ ухудшению качественных и количественных характеристик экосистемы города в цуелом. В рамках работы выполнен анализ основных характеристик грунта которые определяют его эколого химическое состояние, по данным 2012 по 2016 годы. На современном этапе развития экологической науки актуальным является вопрос оценки состояния 
территорий с помощьюю математического моделирования, которое учитьввает большинство факторов окружающей среды и дает возможность прогнозирования возможных изменений их состояния с достаточной степенью вероятности. В дальнейшем, с помощуью математической модели, будет выполнена оценка состояния почв урбанизированных территорий (на примере города Одесса) при современном уровне антропогенной нагрузки.

Ключевые слова: урбанизированные территории, качество почв, математическая модель, эколого - химическая оченка, антропогенная нагрузка.

\section{ANALYSIS OF ECOLOGICAL - CHEMICAL STATUS OF SOILS OF M.DESA FOR THE AIMS OF MODELING THE QUALITY OF SOILS OF URBANIZED TERRITORIES Ilina $\mathrm{V}$.}

The city of Odessa is one of the most loaded urban areas. This is due to many factors, the main of which is the lack of underground, which causes a significant load on the soil due to road transport and other transport systems. Due to this, about 80\% of atmospheric air pollution, water environment and soil and vegetation cover are formed, as well as environmental and chemical characteristics of soil quality deteriorate, which in turn leads to deterioration of the qualitative and quantitative characteristics of the city ecosystem as a whole. In the framework of the work, the analysis of the main characteristics of the soil that determine its ecological and chemical status, according to the data for 2012 to 2016 years. At the present stage of development of ecological science, the question of assessing the state of territories with the help of mathematical modeling, which takes into account the majority of environmental factors and provides an opportunity to predict possible changes in their state with a sufficient degree of probability, is relevant. Subsequently, with the help of a mathematical model, an assessment of the condition of the soils of urbanized territories (for example, the city of Odessa) will be performed at the current level of anthropogenic loading.

Key words: urbanized territories, soil quality, mathematical model, ecological chemical estimation, anthropogenic loading. 